\title{
La astucia de la Corte Suprema de Justicia de la Nación: argumentos para el rechazo o para la declaración de certeza pretendida respecto del art. 30 del Reglamento del Senado de la Nación
}

The inventiveness of Supreme Court of Argentina: arguments for the rejection or for the declaration of alleged certainty regarding art. 30 of the Regulations of the Senate of the Nation A astúcia do Supremo Tribunal de Justiça da Nação: argumentos para a rejeição ou para a declaração de suposta certeza quanto ao art. 30 do Regulamento do Senado da Nação L'astuce de la Cour Suprême de Justice de la nation argentine: arguments pour le rejet ou pour la déclaration de certitude alléguée concernant l'art. 30 du Règlement du Sénat de la Nation 国家最高法院的机敏: 拒绝或宣布关于艺术的确定性的论 点. 国家参议院条例三十

Gerónimo Arias ${ }^{1}$ Universidad Nacional de La Plata - Argentina

Revista Derechos en Acción ISSN 2525-1678/ e-ISSN 2525-1686 Año 5/No 16 Invierno 2020 (21 junio a 20 septiembre), 440-455 DOI: https://doi.org/10.24215/25251678e430

Recibido: $13 / 07 / 2020$

Aprobado: 01/08/2020

1 Abogado egresado de la Facultad de Ciencias Jurídicas y Sociales de la Universidad Nacional de La Plata. 
Resumen: El trabajo analiza el fallo de la CSJN en la causa "Fernández de Kirchner, Cristina en carácter de Presidenta del Honorable Senado de la Nación s/ acción declarativa de certeza", del 24/04/2020. Para el autor, la decisión comentada versa sobre un debate jurídico de profunda raíz política. Por esta razón, cree que el derecho, como producto de su tiempo, ha dado un resultado positivo y acorde a las necesidades que la pandemia nos exige, receptando las imperiosas demandadas de un contexto imprevisible. Ello es así, toda vez que esta sentencia, sin comprometerse más allá de lo necesario, lo hizo de manera suficiente para facilitar el camino al Poder Legislativo y que éste cumpla su mandato constitucional, aún en las condiciones excepcionales en las que la presentación de la Presidenta del Senado fue realizada.

Palabras clave: democracia, coronavirus, senado, constitución.

Abstract: This paper analyzes the ruling of the CSJN in the case "Fernández de Kirchner, Cristina as President of the Honorable Senate of the Nation s / declarative action of certainty", of 04/24/2020. For the author, the commented decision is about a legal debate with deep political roots. For this reason, he believes that the law, as a product of its time, has given a positive result and in accordance with the needs that the pandemic demands of us, receiving the imperative demands of an unpredictable context. This is so, since this sentence, without committing itself beyond what is necessary, did so in a sufficient way to facilitate the path to the Legislative Power and for it to fulfill its constitutional mandate, even under the exceptional conditions in which the presentation of the President of the Senate was made.

Keywords: democracy, coronavirus, senate, constitution.

Resumo: 0 trabalho analisa a decisão da CSJN no processo "Fernández de Kirchner, Cristina como Presidente do Honorável Senado da Nação s / ação declarativa de certeza", de 24/04/2020. Para 0 autor, a decisão comentada é sobre um debate jurídico com profundas raízes políticas. Por isso, acredita que a lei, como produto de sua época, tem dado um resultado positivo e de acordo com as necessidades que a pandemia nos exige, recebendo as demandas imperativas de um contexto imprevisível. É assim, visto que esta sentença, sem se comprometer além do necessário, o fez de forma suficiente para facilitar o caminho ao Poder Legislativo e para que cumprisse o seu mandato constitucional, mesmo 
nas condições excepcionais em que a apresentação do Presidente do Senado foi nomeado.

Palavras-chave: democracia, coronavírus, senado, constituição.

Résumé: Cet article analyse la décision du CSJN dans l'affaire "Fernández de Kirchner, Cristina en tant que Président de l'Honorable Sénat de la Nation s /action déclarative de certitude», du 24/04/2020. Pour l'auteur, la décision commentée concerne un débat juridique aux racines politiques profondes. Pour cette raison, il estime que la loi, en tant que produit de son temps, a donné un résultat positif et conforme aux besoins que la pandémie exige de nous, recevant les exigences impératives d'un contexte imprévisible. II en est ainsi, puisque cette phrase, sans s'engager au-delà de ce qui est nécessaire, l'a fait d'une manière suffisante pour faciliter le chemin vers le pouvoir législatif et pour lui permettre de remplir son mandat constitutionnel, même dans les conditions exceptionnelles où la présentation du Président du Sénat a été nommé.

Mot-clés: démocratie, coronavirus, sénat, constitution.

摘要： 这项工作分析了CSJN在2020年4月24日的 “克里斯蒂娜 (Cristina Fernández de Kirchner) 担任国家参议院议长/确定性 行动”一案中的裁决. 对于作者而言, 评论意见是关于具有深厚政治 根源的法律辩论. 因此, 他认为, 法律作为其时代的产物, 已经产生 了积极的结果, 并符合我们对大流行的要求, 接受了不可预测的环 境的迫切要求. 之所以如此, 是因为这句话在没有超出必要范围的 情况下就以充分的方式这样做, 以便利通往立法权的道路, 并使其 得以履行其宪法任务, 即使在这种特殊情况下, 参议院议长就任.

关键词: 民主, 冠状病毒, 参议院, 宪法.

\section{Introducción}

El marco mundial y nacional generado por el COVID-19 puso -y pone en forma permanente- a prueba las instituciones para dar respuesta a una crisis sanitaria, social y económica sin precedentes. El objeto de este trabajo es evidenciar que la disciplina jurídica no es ajena a esta problemática e intenta brindar soluciones a muchas de las incógnitas que se formulan 
diariamente a través de las autoridades, agentes sanitarios, económicos, periodistas y la ciudadanía en general. Ello exige de cierta creatividad y capacidad innovadora para estar a la altura que demanda la hora.

Desde esa perspectiva, y a propósito de la sentencia dictada por la CSJN en la causa "Fernández de Kirchner, Cristina en carácter de Presidenta del Honorable Senado de la Nación s/ acción declarativa de certeza", del 24/04/2020, podemos afirmar que, luego de días de disquisiciones teóricas con más voces en contra que a favor, el máximo tribunal del país dio por finalizado el primer capítulo de lo que Andrés Gil Domínguez calificó como "la democracia digital" (24/04/2020. "La Corte Suprema del siglo XXI habilitó la democracia digital". Recuperado de https://www.infobae.com).

Sabido es que la Vicepresidenta de la Nación, en su carácter de Presidenta del Senado, realizó una presentación ante la CSJN en la que formuló la siguiente pregunta: “Es constitucionalmente posible que tal como lo establece el art. 30 del Reglamento de la H. Cámara de Senadores sesione mediante medios digitales debido a la situación de gravedad institucional generada objetivamente por el COVID19?"

La acción declarativa de certeza fue entablada contra el Estado Nacional en los términos del artículo 322 del Código Procesal Civil y Comercial de la Nación, y tuvo por objeto superar el estado de incertidumbre sobre el alcance del mencionado artículo 30 del Reglamento para sesionar con medios digitales ("Los senadores constituyen Cámara en la sala de sus sesiones y para los objetos de su mandato, salvo en casos de gravedad institucional". Reglamento de la Honorable Cámara de Senadores de la Nación. Recuperado de https://www.senado.gov.ar/ reglamento).

Explicó que el Senado de la Nación adhirió a la normativa que ordenó el aislamiento social, preventivo y obligatorio por resolución RSA-548/2020. Agregó que la mayoría de los senadores y senadoras que integran el cuerpo se encuentran en sus 
provincias de origen, y remarcó las dificultades que implicaría trasladarlos a la Ciudad Autónoma de Buenos Aires para sesionar en forma presencial dada la suspensión del transporte de pasajeros en todo el país. A ello, añadió que la reunión en el recinto implica la ruptura del distanciamiento social obligatorio que la legislación estableció en el marco de la pandemia.

A su vez, la actora afirmó que carecía de otro medio legal para darle fin inmediatamente a dicho estado de incertidumbre, recordando que la admisibilidad de la acción declarativa de certeza no requiere un daño consumado, pues tiene un carácter preventivo, tal como lo decidió la CSJN en el caso "Provincia de Santiago del Estero c/ Gobierno Nacional” (Fallos: 307:1379).

Algunos afirman, sin más, que la CSJN rechazó la acción intentada. Otros, por su parte, intentan desandar su enjundioso y extenso fallo, para así rescatar sus enseñanzas y, con mayor agudeza, aplaudirlo o criticarlo. En cuanto a la tarea emprendida, siempre es bueno recordar que la CSJN tiene el enorme poder de tener la razón principalmente por ser el último órgano jurisdiccional en decidir, más allá del acierto o error de sus argumentaciones.

En ese orden, distintos doctrinarios adelantaron su opinión a través de los medios masivos de comunicación. Lo que discutían -salvo contados constitucionalistas- era si la CSJN iba a rechazar la acción por medio de una resolución que afirmara que no existía caso o que el asunto no era de la competencia originaria del máximo tribunal.

Por su parte, Roberto Gargarella había expuesto, con anterioridad al fallo comentado, el desacierto de los argumentos utilizados para negar la intervención de la CSJN (23/04/2020. "La 'consulta' del Senado a la Corte, y el diálogo entre poderes". Recuperado de https://seminariogargarella.blogspot.com). En esa oportunidad, postuló que la razón principal para admitir dicha intervención del máximo tribunal tenía que ver con la "concepción de la democracia" a partir de la cual el autor se acerca al constitucionalismo, y que se asienta en el "diálogo" o 
la "conversación" colectiva. Conforme con su mirada, en apretada síntesis, la vida democrático-constitucional debe basarse en el diálogo colectivo, que incluye de manera prevalente la "conversación" entre las distintas ramas de poder.

Dicho esto, observamos que la CSJN sorprendió rechazando la acción pero dejando clara su postura respecto de la pregunta que se le formulara, a través de lo que llamamos obiter dictum. Para abordar este concepto, resulta útil recordar que en muchas ocasiones la CSJN resuelve brevemente, o mediante remisión a sus propios precedentes o al dictamen de la Procuración General de la Nación emitido en las actuaciones. Pero en otras oportunidades, como la que comentamos, opta por decir más de lo que hubiera sido mínimamente exigible y suficiente para rechazar o hacer lugar a la acción. Así pues, se conoce como obiter dictum a aquellos argumentos complementarios o accesorios de la decisión principal o holding de la sentencia.

Esta postura es, en mayor o menor medida, compartida por Andrés Gil Dominguez (25/04/2020. "La Corte Suprema del siglo XXI habilitó la democracia digital". Recuperado de https://www.infobae.com), Domingo Rondina (25/04/2020. "La jurisprudencia también es un relato”. Recuperado de https:// www.infobae.com) y Gustavo Arballo (24/04/2020. Recuperado de https://twitter.com/GustArballo), para quienes la sentencia -con sus matices, y sin perjuicio de la denegatoria- despejó la duda planteada y brindó una respuesta satisfactoria para que el Congreso funcione.

Para comprender cabalmente este tipo de decisiones de gobierno (las sentencias) cabe recordar que en derecho no suele haber una única solución posible. Tampoco las respuestas son siempre binarias, por la sencilla razón que no se trata de una disciplina exacta. Aún los más prestigiosos juristas suelen tener debates memorables y adoptar posiciones antagónicas. Esa inteligencia, en el asunto que comentamos, se traduce en tres votos de autoría de los máximos intérpretes de nuestro sistema normativo -uno de mayoría integrado por tres miembros del tribunal, 
otro concurrente y otro en disidencia- que utilizaron distintas argumentaciones para fundar sus posturas, lo que basta para descartar de raíz los análisis simplificados. Formuladas estas digresiones, corresponde adentrarse en el texto de la sentencia.

\section{El voto de mayoría}

Al fundar la decisión mayoritaria, los Jueces Lorenzetti, Maqueda y Highton de Nolasco realizaron una importante reseña jurisprudencial con citas de distintos precedentes cuya lectura recomendamos detenidamente (desde las causas "Ríos" de 1863, Fallos: 1:32; "Calvete" de 1864, Fallos: 1:340; hasta el caso "Barrick" de 2019, Fallos: 342:917).

Con buen criterio, la mayoría de la CSJN sostuvo que "la parálisis causada por la pandemia exige de las instituciones de la República el desarrollo de los mecanismos que sus autoridades consideren necesarios para asegurar la permanencia de sus tareas" (considerando 9). Destacó la importancia del debate parlamentario y la necesidad de seguir sesionando con respeto de las normas sanitarias recomendadas por la OMS y el gobierno. A su vez, ejemplificó con los distintos sistemas remotos adoptados por países extranjeros para sesionar, y en el orden nacional, por algunas provincias argentinas (Mendoza, Salta, Córdoba y Santa Fe).

Por otro lado, en cuanto a la admisibilidad de la acción, la CSJN planteó el asunto en los siguientes términos: ¿la cuestión es justiciable o por el contrario compete al ámbito propio y exclusivo del órgano parlamentario?

La respuesta de la sentencia fue la segunda alternativa propuesta, motivo por el cual el tribunal consideró que no había caso y la demanda debía ser rechazada. Sin perjuicio de ello, el argumento utilizado por la CSJN para el rechazo de la pretensión fue, ni más ni menos, que la certeza que buscaba la Vicepresidenta de la Nación: la discrecionalidad política del Senado para sesionar de manera remota o virtual sin agravio constitucional. 
Añadió que -como principio general- "el ámbito de su control jurisdiccional no alcanza a las decisiones que otros Poderes del Estado adopten dentro de la esfera de competencia que la Constitución Nacional les asigna como propia y exclusiva”. Citó su copiosa jurisprudencia en la materia, en virtud de la cual no constituye cuestión justiciable lo atinente al procedimiento adoptado por el Poder Legislativo para la formación y sanción de las leyes (considerando 12).

Luego, la CSJN desarrolló el concepto en virtud del cual el asunto llevado a su conocimiento no configuraba un caso justiciable, es decir, una "controversia" en sentido estricto.

A la pregunta inicial formulada por la Vicepresidenta de la Nación, el voto mayoritario respondió que la Constitución Nacional nada dice respecto de la modalidad física o remota de las sesiones del Senado, por lo que no hay impedimento constitucional alguno. Para mayor precisión, afirmó que "la posibilidad de que el Senado sesione de manera remota no interfiere con el modo en que la Constitución le impone a esa Cámara ejercer sus atribuciones. En efecto, la Constitución regula ciertos aspectos del modo en que debe funcionar el Poder Legislativo pero nada indica respecto a la modalidad física o remota de sus sesiones" (considerando 16, la cursiva es del original).

Asimismo, es dable destacar que el voto mayoritario calificó con buen criterio -por más que resulte una obviedad- de "absolutamente esencial" el funcionamiento del Congreso de la Nación para el normal desarrollo de la vida constitucional de la Argentina (considerando 17).

Este estilo elíptico sirvió a la mayoría de la CSJN para dar respuesta a una situación crítica sin menguar su propia doctrina (referida a la competencia originaria, la admisibilidad de la acción, las cuestiones políticas, la gravedad institucional, la división de poderes, etc.), y así brindar argumentos suficientes para la luz verde que la Presidenta del Senado solicitó.

De la forma en la que se lleve adelante ese procedimiento parlamentario dependerá que el prudente control del Poder 
Judicial se mantenga, en el supuesto de planteos futuros, dentro de los límites trazados por la CSJN. Mientras se garantice el cumplimiento de los requisitos mínimos e indispensables que condicionan la creación de la ley, la postura de la CSJN -de conformidad con sus precedentes- es que no se introducirá en las facultades privativas de otro poder del estado. En forma clara, significa que mientras no exista un error grosero y evidente en el trámite, el Senado puede sesionar como mejor considere de acuerdo a las circunstancias excepcionalísimas en las que se encuentra el país, ya que ninguna de las cláusulas veta la posibilidad de que las reuniones se lleven a cabo de forma remota.

No obstante, ello no debe inducirnos a error. Si eventualmente el Congreso aprueba una ley que hipotéticamente genera una injerencia en los derechos de una persona (o colectivo de personas) y esta acciona judicialmente, habrá que analizar el caso y las razones que dan fundamento al objeto de la pretensión.

En tal sentido, el tribunal resguardó su conocida potestad de ser el último intérprete de la Constitución Nacional: si aquellos límites se transgreden, se abrirán las puertas de su control.

A modo de guiño final, el voto de mayoría consignó que el juez Lorenzetti suscribió la sentencia en la localidad de Rafaela, Provincia de Santa Fe, en virtud de las medidas de aislamiento social preventivas dispuestas por las autoridades nacionales.

Como si eso fuera poco, nunca faltan las voces que afirman que las sentencias se leen de atrás para adelante, es decir, la parte resolutiva primero y después los fundamentos. La CSJN también les simplificó la tarea a aquellas personas, toda vez que no rechazó, sin más, la acción judicial. Por el contrario, en su parte resolutiva, el voto de mayoría dispuso que "el Senado de la Nación tiene todas las atribuciones constitucionales para interpretar su propio reglamento en cuanto a la manera virtual o remota de sesionar, sin recurrir a la Corte Suprema de Justicia de la Nación", motivo por el cual, ahora sí, rechazó la acción incoada. 


\section{EI voto concurrente del Juez Rosatti}

El voto concurrente del juez Rosatti también merece nuestra atención. Para facilitar la tarea al lector, el considerando 15 sintetizó el resumen de sus ideas. En lo principal, señaló que la acción intentada no correspondía a la competencia de la Corte, porque no había "caso" judicial que resolver.

Consideró que la existencia de gravedad institucional, invocada por la presentante, permitiría soslayar el cumplimiento de los requisitos propios de la vía procesal intentada -o incluso reconducirla por otro medio procesal si se considerara más apto- pero no posibilita obviar la inexistencia de "caso" o "causa" judicial. Asimismo, sostuvo que "es cierto que hay gravedad institucional, pero no es exactamente la invocada en la presentación (supuesta imposibilidad del H. Senado de sancionar leyes que no pueden ser aprobadas por el Presidente por vía de Decretos de Necesidad y Urgencia), sino la afectación del sistema republicano por la alegada falta de funcionamiento de una de las Cámaras del Congreso con la subsecuente imposibilidad de: a) sancionar todo tipo de leyes, y b) ejercer las funciones de control constitucionalmente asignadas".

A ello, añadió que el Senado no solo puede sino que debe sesionar para poder cumplir con su rol constitucional. Y debe hacerlo -refirió- con las modalidades que el propio Senado establezca, y con el temario que el propio Senado determine, porque está en período de sesiones ordinarias.

Por otra parte, introdujo un capítulo novedoso con consideraciones adicionales a título de colaboración entre los poderes del Estado frente a la inédita situación planteada por la proyección de la pandemia en la vida institucional del país (intitulado "Principio de colaboración entre los poderes del Estado. Consideraciones frente a la excepcionalidad de la situación"; considerandos 10 a 14). En lo que aquí importa, indicó que la Constitución no previó el trabajo no presencial de sus integrantes en el marco de las sesiones, sencillamente porque no podía pedírsele a los constituyentes, originarios o reformadores, que 
imaginaran el futuro tecnológico. Ahora bien, precisó que de esa circunstancia no se deriva su prohibición ni la inconstitucionalidad de tal sistema.

Categóricamente, definió que le incumbe al Senado y no a la Corte decidir si aquel debe sesionar en lo sucesivo de modo presencial o no presencial, y -en este último caso- si para hacerlo es necesario interpretar o modificar su reglamento de funcionamiento, tareas ambas que -por obedecer a su modo y forma de organización y funcionamiento- corresponden a la exclusiva competencia de la Cámara.

Más allá del enorme valor de la totalidad del voto concurrente de Rosatti, consideramos que ese es su mayor aporte. En él se encargó de aclarar que el método escogido por el Tribunal para superar las circunstancias actuales y habilitar la modalidad de trabajo a distancia fue la reforma de su propio reglamento, sin perjuicio que -de haber sido más idóneo- hubiera podido optar por la vía interpretativa.

Pensamos que ahí está la clave del trabajo parlamentario. Sin decir cuál es la correcta -porque no corresponde a la CSJN-, sugiere dos soluciones. Si el Senado lo cree conveniente, puede modificar su Reglamento. Pero también, desde otro ángulo, observamos que como representante de la Cámara (artículo 36 del Reglamento de la Cámara de Senadores) la Presidenta del Senado tiene las atribuciones necesarias para interpretar el reglamento y avanzar con una sesión no presencial o remota. Creemos que cualquier alternativa debería ser precedida de acuerdo parlamentarios, a fin de dotar a aquella decisión de mayor fuerza democrática mediante el acompañamiento de los distintos bloques del cuerpo colegiado.

En otro orden, Rosatti fue enfático en afirmar que la eventual revisión judicial -respecto de la modalidad presencial o virtual de sesión-, en el supuesto que se articulara un caso o controversia al respecto, debería realizarse con particular restricción.

Quizás eso no sea un blindaje a las leyes que puedan sancionarse mediante la modalidad remota o virtual, pero sí 
constituye una postura clara respecto de la pregunta que la Presidenta del Senado le formuló a la CSJN. Para concluir, Rosatti también firmó la sentencia en la localidad de Santa Fe, Provincia de Santa Fe.

\section{El voto en disidencia del Juez Rosenkrantz}

El Juez Rosenkrantz resolvió que la presentación analizada debía ser rechazada in limine. A diferencia de sus colegas preopinantes, se limitó -con cierto dogmatismo- a considerar las imposibilidades procesales que ya habían sido expuestas por el Procurador General Interino.

Sucintamente, expuso que la solicitud formulada no constituía acción o recurso alguno que, con arreglo a los artículos 116 y 117 de la Constitución Nacional, habilite la intervención pretendida de la CSJN. A ello, añadió que "resulta manifiesto el carácter puramente consultivo de la solicitud y la inexistencia de un 'caso' o 'controversia'".

Argumentó que no puede haber caso sin contraparte y más allá de la mención nominal del Estado Nacional en el escrito inicial no se había identificado "ninguna contraparte concreta respecto de la cual exista una controversia actual que deba ser saldada para resolver una colisión de intereses o derechos".

Recordó que en nuestro sistema constitucional la existencia de un caso judicial es una precondición para la intervención de los tribunales nacionales y constituye un requisito sine qua non de su accionar (artículo 116, Constitución Nacional; artículo $2^{\circ}$, ley 27). Agregó que ello es así con absoluta independencia del mérito o la trascendencia política o de otra naturaleza que pueda tener el planteo que se pretende someter al estrado judicial.

Con un criterio estricto, expuso que más allá de la gravedad de la situación nacional, la CSJN y los tribunales inferiores no pueden convertirse en órganos de consulta de los restantes poderes del Estado.

Ponderó que la presentación analizada era abstracta y previa a toda situación jurídicamente contenciosa, por lo que 
"importa -en verdad- la pretensión de que esta Corte ejerza una suerte de control de constitucionalidad, abstracto, previo y concentrado, característico de diseños institucionales que resultan radicalmente ajenos al sistema de la Constitución Nacional".

En cuanto a la gravedad institucional, consideró que tal doctrina no puede ser utilizada para deformar o eludir las exigencias a las que la intervención de la CSJN está constitucionalmente supeditada.

Sin perjuicio de ello, mencionó que aun cuando se considerase que el pedido de la señora Vicepresidenta de la Nación constituye una demanda declarativa de certeza y no una mera consulta, igualmente correspondería desestimar la presentación. Ello es así -detalló- porque, al no ser parte actora ni demandada una provincia, la demanda se encontraría, por razones de índole constitucional, fuera de la competencia originaria del Tribunal (cfr. artículo 117, Constitución Nacional), tal como señaló el señor Procurador General interino en su dictamen.

En comparación con el voto de sus colegas, observamos en la decisión del juez Rosenkrantz y -principalmente- en su forma de argumentarla, una mirada más instrumental que preocupada por el resultado. Como dijo en su discurso de apertura del año judicial 2019, en su calidad de Presidente de la CSJN, el juez debe ser capaz -según su mirada- de actuar sin pensar en las simpatías o antipatías que pueda generar su decisión, lo que importa alejarse de la realidad que lo rodea.

\section{Conclusiones}

El fallo comentado versa sobre un debate jurídico de profunda raíz política. Por esta razón, creemos que el derecho, como producto de su tiempo, ha dado un resultado positivo y acorde a las necesidades que la pandemia nos exige, receptando las imperiosas demandadas de un contexto imprevisible. Ello es así, toda vez que esta sentencia, sin comprometerse más allá de lo necesario, lo hizo de manera suficiente para facilitar el camino al Poder Legislativo y que éste cumpla su mandato 
constitucional, aún en las condiciones excepcionales en las que la presentación de la Presidenta del Senado fue realizada.

Quizás la estrategia legal por ella utilizada no resulte compartida, pero no se le podrá reprochar que no logró el efecto buscado: comprometer a otro a poder del Estado en una decisión política con el objeto de dotarla de certeza y de una mayor legitimidad democrática. La demanda interpuesta fue efectiva, lo que merece el reconocimiento a la Dra. Graciana Peñafort y el Dr. Esteban Lopardo, patrocinantes de la presentación formulada.

Asimismo, entendemos que el voto mayoritario -incluido el concurrente del Dr. Rosatti- importó un ejercicio responsable que ponderó las consecuencias de las decisiones institucionales, lejos de desentenderse de las acuciantes problemáticas que aquejan a la sociedad y a las que el Congreso de la Nación debe dedicarse con premura. Resulta evidente, entonces, que cuando la CSJN quiere resolver un caso (o un no caso), lo hace.

Desde una mirada jurídica, se abren interrogantes respecto del diálogo entre los poderes del Estado. ¿Es valioso que la CSJN diga más de lo necesario para resolver un asunto o, por el contrario, implica un riesgo institucional que abre un camino desconocido respecto de sus consecuencias futuras? ¿En qué casos la CSJN emitirá consideraciones a título de "colaboración entre los poderes del Estado", como explícitamente precisó el Juez Rosatti? ¿Fortalece la democracia y las instituciones republicanas el diálogo entre poderes o es un intento de compartir responsabilidades exclusivas inherentes a la división de poderes?

Más allá de las respuestas que busquemos a esos interrogantes, la posibilidad de desarrollar prácticas dialógicas entre poderes es un escenario que con que este fallo la CSJN muestra alguna voluntad de favorecer. La discusión y la contribución para la resolución de conflictos en momentos de crisis profundas se vuelve un imperativo para la defensa de la institucionalidad democrática, en tanto disuade el abuso del poder ejercido en ausencia de consensos.

De alguna manera, la presentación realizada y la consiguiente respuesta del máximo tribunal, se inscriben en ese 
marco de diálogo de poderes, para intentar al menos distribuir o compartir la razón. En el caso comentado, creemos que esa interacción del poder volvió a poner -con mayor fuerza y legitimidad- a la política en el centro de la escena democrática para la toma de decisiones.

Por último, desde el punto de vista político, habrá quienes vean la sentencia que comentamos como una derrota del gobierno y otros como una victoria. Por nuestra parte creemos que la Vicepresidenta de la Nación logró su objetivo, tal como ella misma lo manifestó mediante sus redes sociales.

Ello fue confirmado el miércoles 13 de mayo de 2020 con la realización de la primera sesión virtual en la historia del Congreso de la Nación. En dicha oportunidad, el Senado Nacional trató y aprobó 20 Decretos de Necesidad y Urgencia firmados por el Presidente Alberto Fernández en el marco de la pandemia. En el recinto estuvieron las autoridades de la Cámara, mientras que el resto de los senadores y las senadoras estuvieron en despachos oficiales o en sus casas siguiendo el debate en forma remota. Previamente, se habían sometido a las pruebas de validación de identidad, con la colaboración técnica del Registro Nacional de las Personas dependiente del Ministerio del Interior. Solamente se ausentó un senador por encontrarse de licencia.

De esta forma, Cristina Fernández de Kirchner generó un precedente que seguramente será estudiado por los y las constitucionalistas de nuestra generación y las futuras. Lo concreto es que el fallo comentado nos dejó una certeza jurídica: sí, es constitucionalmente posible que el Congreso sesione mediante medios digitales.

\section{Bibliografía}

Corte Suprema de Justicia de la Nación (1985) Provincia de Santiago del Estero c/Gobierno Nacional. En línea en: http://www. revistarap.com.ar/Derecho/administrativo/aranceles_honorarios/santiago_del_estero_provincia_de_c_estado_nacion.html 
Dominguez, Andrés Gil (2020) La Corte Suprema del siglo XXI habilitó la democracia digital En línea en: https://www.infobae.com/opinion/2020/04/25/la-corte-suprema-del-siglo-xxihabilito-la-democracia-digital/

Gargarella, Roberto (2020) La 'consulta' del Senado a la Corte, y el diálogo entre poderes. En línea en: http://seminariogargarella.blogspot.com/2020/04/la-consulta-del-senado-la-corte-yel.html

Rondina, Domingo (2020) La jurisprudencia también es un relato. En línea en: https://www.infobae.com/opinion/2020/04/25/ la-jurisprudencia-tambien-es-un-relato/

Senado Argentino (2016) Reglamento de la Cámara de Senadores. En línea en: https://www.senado.gob.ar/reglamento 